\title{
DIAGNÓSTICO AMBIENTAL DA BACIA HIDROGRÁFICA DO RIO MAMPITUBA, REGIÃO SUL DO BRASIL, UTILIZANDO A MATRIZ FPEIR
}

\author{
Daniel Trespach Porto ${ }^{1}$ \\ Luís Alberto Basso² \\ Tânia Marques Strohaecker ${ }^{3}$
}

Resumo: O objetivo deste trabalho foi diagnosticar a situação dos recursos hídricos da Bacia Hidrográfica do Rio Mampituba (BHRM), região sul do Brasil. Utilizou-se o método da matriz de indicadores socioambientais FPEIR (Força Motriz, Pressão, Estado, Impacto e Resposta). Após síntese e classificação dos dados, os mesmos foram mapeados por sub-bacias. Verificou-se que a sustentabilidade ambiental da maior parte da BHRM encontra-se em situação regular. As principais atividades geradoras de pressão são agricultura, indústria e urbanização, mas de modo geral a pressão antrópica é baixa. Entretanto, constata-se a vulnerabilidade da BHRM pela falta de infraestrutura de abastecimento de água e saneamento e de ações de monitoramento, proteção e gestão ambiental, ou seja, pela escassez de medidas de resposta adequadas.

Palavras-chave: Gestão de recursos hídricos. Indicadores socioambientais. Litoral Norte do Rio Grande do Sul. Litoral Sul de Santa Catarina. Uso e ocupação do solo.

\section{ENVIRONMENTAL DIAGNOSIS OF THE HYDROGRAPHIC BASIN OF THE MAMPITUBA RIVER, SOUTH REGION OF BRAZIL, USING THE DPSIR FRAMEWORK}

Abstract: The objective of this work was to diagnose the water resources situation of the Mampituba River Basin (MRB), southern region of Brazil. The method of the DPSIR socioenvironmental indicators matrix (Driving Force, Pressure, State, Impact and Response) was used. After synthesis and classification of the data, they were mapped by sub-basins. It was verified that the environmental sustainability of most of the $\mathrm{MRB}$ is in a regular situation. The main pressure-generating activities are agriculture, industry, and urbanization, but overall anthropogenic pressure is low. However, the vulnerability of MRB is evidenced by the lack of water supply and sanitation infrastructure and monitoring, protection and environmental management actions, due to the lack of adequate response measures.

Keywords: Water resources management. Social and environmental indicators. Northen Coast of Rio Grande do Sul. South Coast of Santa Catarina. Land use.

\section{DIAGNÓSTICO DE LA CUENCA HIDROGRÁFICA DEL RIO MAMPITUBA, REGIÓN SUR DE BRASIL, UTILIZANDO LA MATRIZ FPEIR}

Resumen: El objetivo de este trabajo fue diagnosticar la situación de los recursos hídricos de la Cuenca Hidrográfica del Río Mampituba (CHRM), región sur de Brasil. Se utilizó el método de la matriz de indicadores socioambientales FPEIR (Fuerza

\footnotetext{
${ }^{1}$ Universidade Federal do Rio Grande do Sul, Departamento de Geografia, Porto Alegre, Brasil, portodt@outlook.com, https://orcid.org/ 0000-0002-8097-4926

${ }_{2}^{2}$ Universidade Federal do Rio Grande do Sul, Departamento de Geografia, Porto Alegre, Brasil, lbasso@terra.com.br, https://orcid.org/0000-0002-1014-8039

${ }^{3}$ Universidade Federal do Rio Grande do Sul, Departamento de Geografia, Porto Alegre, Brasil, tania.strohaecker@ufrgs.br, https://orcid.org/0000-0001-7462-6944
} 
Motriz, Presión, Estado, Impacto y Respuesta). Después de la síntesis y clasificación de los datos, los mismos fueron mapeados por subcuencas. Se ha comprobado que la sostenibilidad medioambiental de la mayoría de la CHRM se encuentra en situación regular. Las principales actividades generadoras de presión son la agricultura, la industria y la urbanización, pero en general la presión antrópica es baja. Sin embargo, se constata la vulnerabilidad de la CHRM por la falta de infraestructura de abastecimiento de agua y saneamiento y de acciones de monitoreo, protección y gestión ambiental, o sea, por la escasez de medidas de respuesta adecuadas.

Palabras clave: Gestión de recursos hídricos. Indicadores socioambientales. Litoral Norte de Rio Grande do Sul. Litoral Sur de Santa Catarina. Uso del suelo.

\section{INTRODUÇÃO}

Para a manutenção da vida, a água é de importância fundamental, sendo a principal substância constituinte dos organismos. Por esse motivo, se faz tão necessário o conhecimento da sua distribuição, quantidade e dinâmica em nosso planeta. Na Terra, cerca de $97 \%$ da água encontra-se nos oceanos, 2,2\%, nas geleiras e apenas $0,8 \%$ está na forma de água doce, propícia para consumo humano. E dessa, cerca de $97 \%$ encontra-se no subsolo e apenas $3 \%$ na superfície, onde a extração é mais fácil. A partir desses dados, percebe-se a importância que adquire a conservação dos recursos hídricos do planeta (SPERLING, 1996).

A ação humana, quando altera a qualidade ambiental modificando processos naturais ou sociais, resulta em impacto ambiental, que pode ser positivo ou negativo. Quando esse impacto é negativo, degrada o ambiente, causa alterações adversas nos processos, funções ou componentes ambientais (SÁNCHEZ, 2013). Ou seja, em se tratando da água, sua qualidade é frequentemente alterada por impactos negativos das atividades humanas e os usos requeridos, que modificam o ciclo hidrológico, suas funções ecológicas e seus componentes constituintes.

Além do uso da água, o uso da terra para atividades humanas tem grande capacidade para alterar o ambiente (indústrias, abastecimento e saneamento doméstico, agricultura, etc.) por gerarem consumo excessivo do recurso, despejos de cargas poluentes, aumento do assoreamento, modificação da paisagem e diminuição das áreas de vegetação nativa. A dinâmica do uso e da cobertura da terra em uma bacia hidrográfica tem grande influência na qualidade ambiental de seus recursos hídricos, sendo importante seu estudo e a elaboração de indicadores socioambientais para subsidiar o gerenciamento das águas e políticas de ordenamento territorial visando a preservação dos recursos naturais. 
Devido ao crescimento da demanda, principalmente pelo crescimento populacional, pela urbanização, pelo desenvolvimento industrial, pela crescente produção de alimentos a expansão agrícola, entre outros, vem diminuindo significativamente a disponibilidade de água potável. O estado atual de degradação ambiental sugere repensar como devem ser utilizados os recursos naturais, em especial os hídricos, exigindo dos gestores e da população, novos comportamentos e estratégias de planejamento que minimizem os impactos (BASSO, 1999).

O presente trabalho busca responder a seguinte questão: qual a situação dos recursos hídricos da Bacia Hidrográfica do Rio Mampituba (BHRM)? Tendo como como objetivo principal elaborar uma síntese da situação dos recursos hídricos da BHRM a partir da utilização da matriz de indicadores socioambientais FPEIR (Força Motriz, Pressão, Estado, Impacto e Resposta), que será apresentada adiante.

A escolha da BHRM deve-se à escassez de estudos sobre a mesma, por ser uma bacia interestadual, com instrumentos de ordenamento territorial de dois estados atuando sobre sua dinâmica, e pela diversidade de usos observados, do urbano ao agrícola. A atuação do estado através de seus instrumentos de gestão territorial e os usos que a sociedade faz da terra e dos recursos da bacia, principalmente das águas, interferem nos seus ecossistemas e na disponibilidade dos serviços ambientais.

Planos de gerenciamento de recursos hídricos de bacias interestaduais, assim como planos nacionais e regionais de ordenação territorial, são de competência da União. Pela ocorrência de sobreposições de recortes espaciais de planejamento e gestão que geram situações de conflitos entre instâncias de ordenamento territorial, seus instrumentos deveriam ser integrados, migrando a dimensão ambiental de uma lógica setorial para uma lógica territorial (PERES e SILVA, 2013).

Assim, o estudo da influência dessas variáveis e da situação das águas da BHRM se faz necessário, ampliando o conhecimento sobre a sua dinâmica socioambiental para que se obtenham subsídios para a elaboração de políticas e instrumentos mais efetivos de ordenamento territorial e gestão ambiental.

\section{Planejamento ambiental e gestão dos recursos hídricos}

O planejamento ambiental pode ser definido como o conjunto de ações adequadas à potencialidade, à vocação e à capacidade de suporte de uma determinada região, visando um desenvolvimento harmônico e a manutenção da 
qualidade dos meios social, físico e biológico (SANTOS, 2004). Portanto, orientado pelas potencialidades e fragilidades da região, o planejamento ambiental considera a vocação local para adequar a exploração dos recursos naturais e o uso da terra, determinando a proteção aos ecossistemas como limite para as demandas sociais e estas como redutoras das demandas econômicas.

Os processos de industrialização e urbanização acelerados, fenômenos típicos do modelo desenvolvimentista adotado no Brasil a partir da década de 1960, contribuíram para agravar a situação dos recursos naturais. A partir da década de 1980, a preocupação com a gestão dos recursos hídricos ganha vigor (BASSO, 1999).

No país, a proteção e gestão dos recursos hídricos têm como marcos legislativos a Política Nacional de Recursos Hídricos (PNRH) e a criação do Sistema de Gerenciamento de Recursos Hídricos (SINGREH), em 1997, e a criação da ANA, em 2000, e. A legislação criou uma série de instrumentos de gestão para as águas, como a outorga de direito de uso, sendo o principal o Plano de Recursos Hídricos (PRH), cujo papel é estabelecer as diretrizes de aplicação dos demais instrumentos para cada bacia hidrográfica. (ANA, 2013).

Nesse sentido, a gestão dos recursos hídricos considera a vocação local para adequar o uso das águas, através do enquadramento e da outorga, por exemplo. No entanto, as demandas socioeconômicas ainda não sofrem limitações, pois os PRH não abrangem o ordenamento do uso da terra, que influencia na qualidade e quantidade dos recursos.

\section{Usos e impactos dos recursos hídricos}

Os usos humanos procuram atender necessidades como irrigação, indústria, produção de energia e navegação. $O$ impacto ambiental é a "alteração da qualidade ambiental que resulta da modificação de processos naturais ou sociais provocada por ação humana", podendo ser negativo ou positivo (SÁNCHEZ, 2013). No caso dos recursos hídricos, os impactos são resultado dos usos da água e da terra. Os usos consuntivos, que alteram o volume dos corpos d'água (abastecimento humano, dessedentação de animais, irrigação, indústria) impactam na disponibilidade hídrica. Já os efluentes impactam na qualidade das águas, como o pluvial que ajuda na infiltração de contaminantes agrícolas, de mineração e da pecuária, e do doméstico sem tratamento adequado. Além disso, obras de infraestrutura, como a construção de barragens podem impactar as águas (TUCCI e MENDES, 2006). 
O uso da terra tem impacto sobre os recursos hídricos. Agricultura, mineração, construção e urbanização podem causar ou acelerar processos erosivos. Já o desmatamento e a queima de matas podem alterar a cobertura do solo interferindo no escoamento superficial e na infiltração da chuva (TUCCI e MENDES, 2006).

\section{Indicadores socioambientais}

Indicadores socioambientais apontam tendências na situação do meio ambiente, servindo também para monitorar o progresso na direção das metas das políticas ambientais, explicitando informações sobre fenômenos típicos e críticos para a qualidade ambiental de forma simples e concentrando-se em certos aspectos considerados mais relevantes (EEA, 1999).

Dentre os métodos que buscam representar as relações de causa e efeito entre os fenômenos que ocorrem em determinado recorte geográfico, destacam-se o PER (Pressão, Estado e Resposta) desenvolvido pela OCDE, o FER (Força Motriz, Estado e Resposta) da Comissão de Desenvolvimento Sustentável da ONU e o FPEIR (Força Motriz, Pressão, Estado, Impacto e Resposta) desenvolvido pela European Environment Agency (EEA) (SOARES et al., 2011). Esse último é adotado pela Water Framework Directive (WFD) da União Europeia e, no Brasil, pelo IPT, prefeituras e pesquisadores para diagnósticos ambientais e de bacias hidrográficas (IPT, 2008; IPT e PREFEITURA DE ITANHAÉM, 2012; VAZ e SILVEIRA, 2014; MEDEIROS, 2017; COBRAPE, 2010; IRRIGART, 2009). Neste trabalho, especificamente, foi utilizada a matriz de indicadores FPEIR, que se baseia na análise sistêmica das relações causais entre o ambiente natural e as atividades humanas, conforme indica a Figura 1.

As atividades decorrentes do desenvolvimento socioeconômico funcionam como força motriz, exercendo pressão sobre o ambiente e os recursos hídricos, modificando o estado dos mesmos. Essa alteração pode provocar impactos ambientais, como poluição, conflitos de uso da água, desastres ou problemas de saúde pública, necessitando a adoção de medidas de resposta para prevenção e correção que, dependendo do caso, podem ser aplicadas nas forças motrizes, pressões, estado ou impactos. 


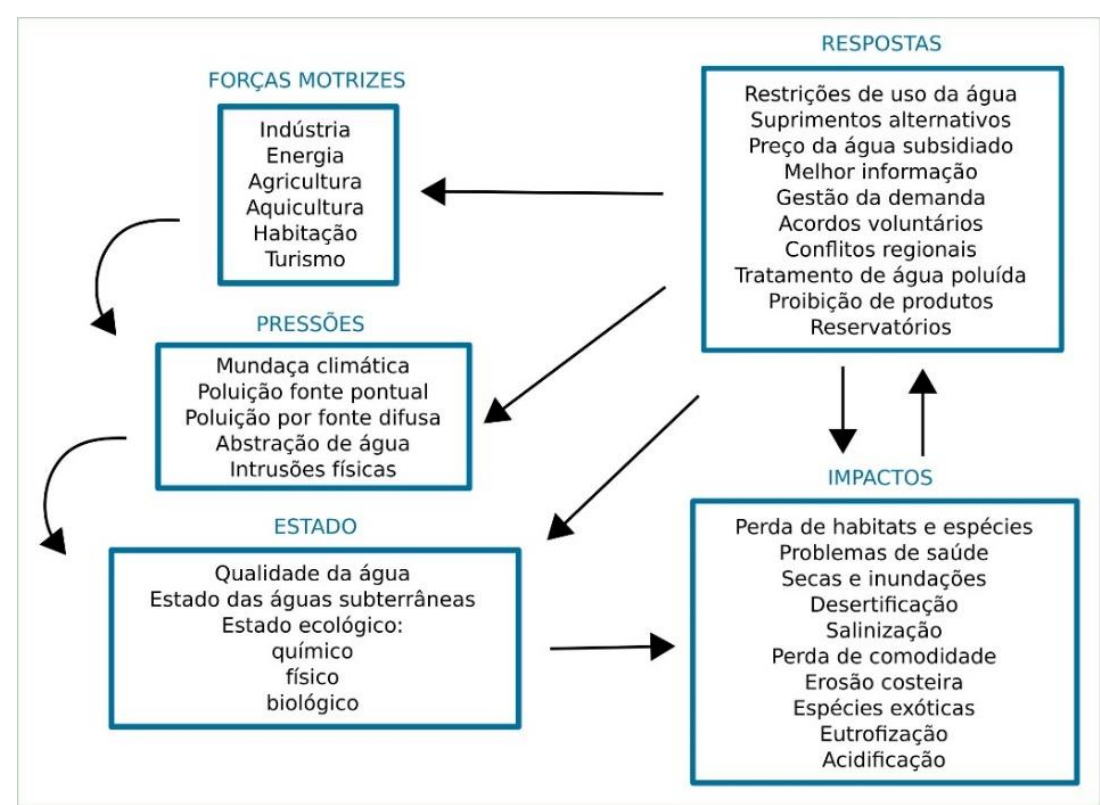

Figura 1 - Indicadores da matriz FPEIR (Fonte: EEA modificado pelos autores)

A Figura 1 apresenta os elementos da matriz FPEIR e seu fluxo causal. Por exemplo, a agricultura funciona como força motriz que gera pressão no meio através do aumento da captação de água, o que altera o estado da disponibilidade hídrica. Isso causa impactos, como o aumento dos conflitos pelo uso do recurso. Surge então a necessidade de elaboração de medidas de resposta à essa situação, como monitoramento da vazão dos cursos d'água e ordenamento do uso do solo.

\section{Área de estudo}

A área pesquisada é a Bacia Hidrográfica do Rio Mampituba (BHRM), localizada no litoral sul do Brasil, entre os estados do Rio Grande do Sul e Santa Catarina, com cerca de $60 \%$ de sua área no primeiro e $40 \%$ no segundo, de um total de $1.777,57 \mathrm{~km}^{2}$ de área de drenagem. Inserida na região hidrográfica Atlântico Sul, e abrangida por 18 municípios (Mapa 1), sendo oito gaúchos (Cambará do Sul, Dom Pedro de Alcântara, Mampituba, Morrinhos do Sul, São Francisco de Paula, Torres, Três Cachoeiras e Três Forquilhas) e dez catarinenses (Araranguá, Balneário Arroio do Silva, Balneário Gaivota, Ermo, Jacinto Machado, Passo de Torres, Praia Grande, Santa Rosa do Sul, Sombrio e São João do Sul). A bacia é interestadual e seu comitê de gerenciamento, criado em 2012, ainda não elaborou o PRH. 


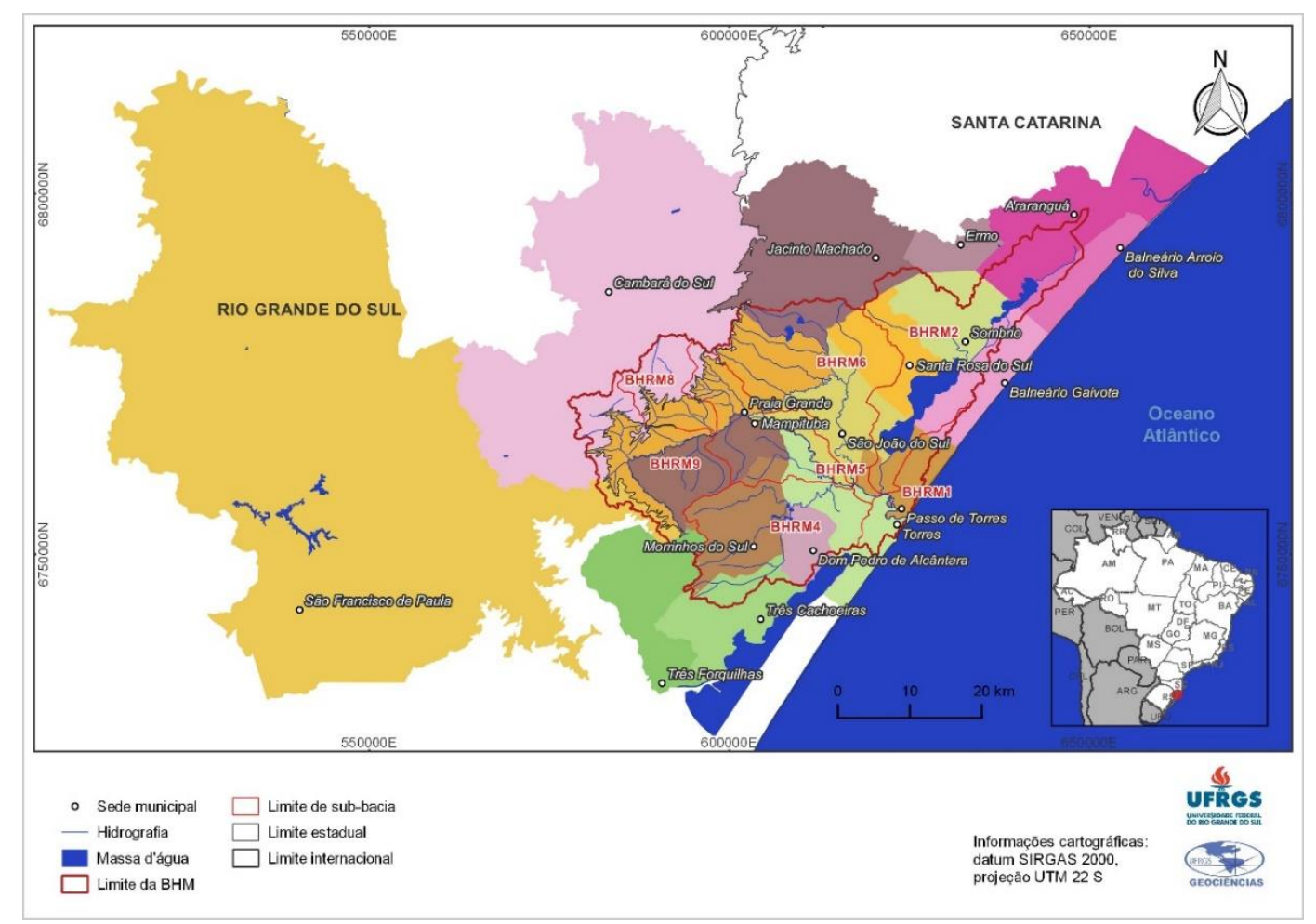

Mapa 1 - Localização da BHRM (Fontes: IBGE, 2015; elaborado pelos autores)

Em termos litológicos, a BHRM situa-se na província litoestrutural Mantiqueira, abrangendo as formações Rio do Rastro, Botucatu, Serra Geral, Chuí e Itapoã e depósitos aluvionares, coluviões e depósitos marinhos. Quanto à geomorfologia, compreende três regiões, a do Planalto das Araucárias, com as unidades geomorfológicas do Planalto dos Campos Gerais, do Planalto da Serra Geral e dos Patamares da Serra Geral; a Planície Continental, com a unidade da Planície Alúvio-Coluvionar; e a Planície Costeira Interna com as unidades da Planície Litorânea e da Planície Lagunar, sendo esta última a de maior área (IBGE, 2003a, 2003b).

Quanto à hidrografia, apresenta uma rede de drenagem abundante, com numerosas vertentes e olhos d'água que abastecem diversos riachos que, quando se unem, formam banhados e auxiliam na fertilização do solo, utilizado para vários tipos de culturas (HINATA e BASSO, 2017). O principal curso d'água é o rio Mampituba, que serve de divisa estadual. Seus principais afluentes são o rio Pavão, na área de contribuição da BHRM-8, o arroio Josafaz, na BHRM-9, o Rio do Sertão, na BHRM-6, o Rio do Mengue, na BHRM-4, e a Lagoa do Sombrio, na BHRM-2 (Mapa 2). 


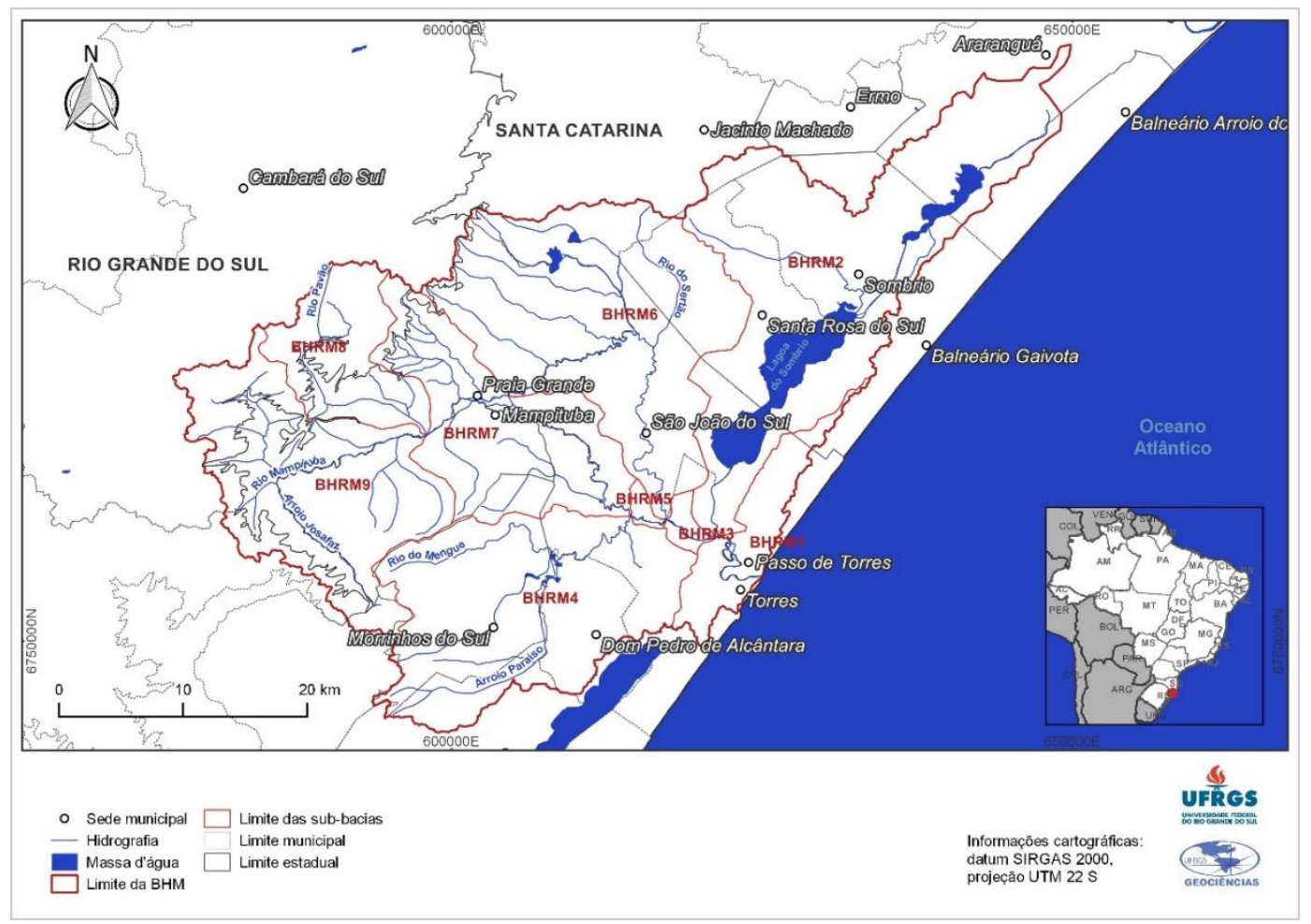

Mapa 2 - Hidrografia principal e sub-bacias da BHRM (Fontes: IBGE, 2015; elaborado pelos autores)

Segundo o sistema de classificação climática de Köppen, a BHRM está sob um clima Cfa com verão quente, ou seja, úmido subtropical de clima oceânico, sem estação seca (ALVARES et al., 2014). Segundo Rossato (2011), a bacia situa-se em zona de transição entre tipos climáticos. A porção do Planalto e da Serra Geral enquadra-se como Subtropical III, úmido com variação longitudinal das temperaturas médias, precipitações altas, entre $1.700 \mathrm{~mm}$ e $1.800 \mathrm{~mm}$ ao ano. A temperatura média anual varia entre $17^{\circ} \mathrm{C}$ e $20^{\circ} \mathrm{C}$. Já o setor das planícies classifica-se como Subtropical IVb, muito úmido com inverno frio e verão fresco, com precipitações bem distribuídas e abundantes, entre $1.700 \mathrm{~mm}$ e $1.900 \mathrm{~mm}$ anuais, e a temperatura média oscilando entre $14{ }^{\circ} \mathrm{C}$ e $17^{\circ} \mathrm{C}$.

O setor agrícola ocupa $22,4 \%$ da área da BHRM, chegando a $73 \%$ na BHRM5. Mas a maior área de uso é na BHRM-6, com 123,9 km². A silvicultura alcança quase $10 \%$ na BHRM-1 e chega a $6,6 \%$ na BHRM-6. Na totalidade, a BHRM tem $3,3 \%$ de sua área ocupada com a silvicultura. As classes de uso pastagem e campo também ocupam grandes áreas, alcançando quase $40 \%$ da BHRM e chegando a $58,9 \%$ na BHRM-4. A cobertura de mata é considerável na bacia, $23,8 \%$, com a BHRM-8 e BHRM-9 colaborando com índices de $52,8 \%$ e $60,2 \%$, respectivamente (Tabela 1).

O uso urbano apresenta três núcleos principais. Um abrange porção da área urbana do município de Araranguá, na BHRM-2; outro contém a sede do município 
de Sombrio, também na BHRM-2; e o terceiro contempla as sedes dos municípios de Torres e Passo de Torres, na foz do rio Mampituba, na BHRM-1. Na BHRM-3 há uma área urbana considerável, proporcionalmente à área da bacia (Mapa 3). $\mathrm{A}$ cobertura de solo exposto se destaca na BHRM-1, com 13,2\%, com manchas nas bordas e próximas à área de uso urbano. Nas demais sub-bacias, o solo exposto está associado às áreas de uso agrícola.

Tabela 1 - Áreas das classes de uso e cobertura da terra

\begin{tabular}{|c|c|c|c|c|c|c|c|c|c|c|}
\hline Classe & BHRM & BHRM-1 & BHRM-2 & BHRM-3 & BHRM-4 & BHRM-5 & BHRM-6 & BHRM-7 & BHRM-8 & BHRM-9 \\
\hline Mata & 23,7 & 10,6 & 14,5 & 6,0 & 17,4 & 5,6 & 14,2 & 17,2 & 52,8 & 60,2 \\
\hline Solo exposto & 1,2 & 13,2 & 5,1 & 1,0 & 1,0 & 0,4 & 2,4 & 0,0 & 0,0 & 0,0 \\
\hline Agricultura & 22,4 & 22,1 & 26,2 & 50,6 & 17,9 & 73,0 & 33,8 & 34,1 & 2,5 & 2,7 \\
\hline Corpo d'água & 2,9 & 0,0 & 10,5 & 0,1 & 1,1 & 0,0 & 0,5 & 0,0 & 0,0 & 0,0 \\
\hline Campo/pastagem & 39,3 & 26,3 & 40,7 & 36,4 & 58,9 & 21,0 & 41,3 & 48,0 & 44,7 & $\overline{37,1}$ \\
\hline Urbano & 1,3 & 5,0 & 3,0 & 5,8 & 0,5 & 0,0 & 0,2 & 1,3 & 0,0 & 0,0 \\
\hline$\overline{\text { Silvicultura }}$ & 3,3 & 9,2 & 3,8 & 0,0 & 3,1 & 0,0 & 6,6 & 0,7 & 0,0 & 0,0 \\
\hline
\end{tabular}

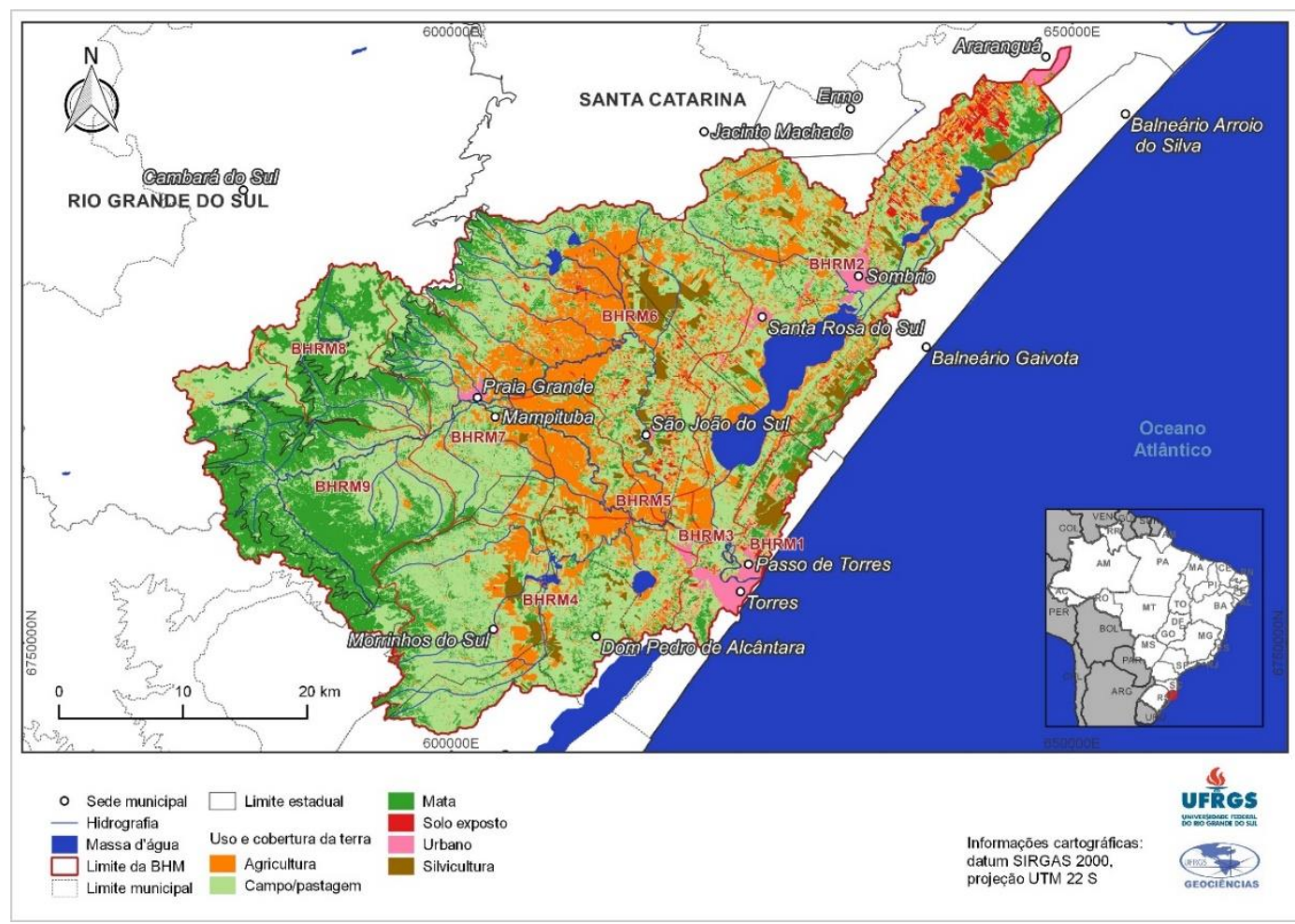

Mapa 3 - Uso e cobertura da terra na BHRM (Fonte: elaborado pelos autores)

\section{METODOLOGIA}

Em ambiente SIG, a delimitação da BHRM e suas sub-bacias foi obtida com vetorização manual dos divisores de águas sobre as curvas de nível geradas a partir de dados de radar da SRTM da United States Geological Survey (USGS), de 2000. Os dados foram processados no programa SAGA-GIS 2.3.1. Para delimitar as sub- 
bacias, foi utilizada a codificação de Otto Pfafstetter, método oficial no Brasil para codificação de bacias hidrográficas.

O levantamento de uso e cobertura da terra foi realizado, também em SIG, a partir de imagem orbital obtida pelo sensor OLI do satélite Landsat-8, com resolução espacial de 30 metros, na data de 15 de maio de 2017. No programa QGIS 2.18.9, utilizou-se o complemento SCP 5.3.11 para as correções radiométrica e atmosférica e a classificação da imagem, resultando nas seguintes classes de uso e cobertura: mata, solo exposto, agricultura, corpo d'água, campo/pastagem, urbano e silvicultura.

Para atingir a elaboração da matriz FPEIR e a caracterização geral da região da bacia, foram levantados os dados populacionais e socioeconômicos do IBGE, IPEA, PNUD e Fundação João Pinheiro; demanda de água da ANA e SEMA-RS; saneamento do SNIS; balneabilidade da FEPAM; doenças de veiculação hídrica do DataSUS; terras indígenas da FUNAI e quilombolas do INCRA.

No levantamento, buscou-se parâmetros que melhor se enquadrassem nos temas da matriz FPEIR (Figura 1), segundo EEA (1999) e IPT (2008). Além disso, eles deveriam representar as condições do meio, ser facilmente interpretados, possibilitar análise de tendências, refletir as mudanças nos meios naturais e antrópicos, e ter valores de referência (SOARES et al., 2011). A disponibilidade de dados foi um problema encontrado no levantamento, pois nem todos os parâmetros eram acessíveis ou não havia informações para todos os municípios.

Foi construída uma tabela integrando os parâmetros de Força Motriz, Pressão, Estado, Impacto e Resposta. Após, os parâmetros foram normalizados, para cada sub-bacia e para a BHRM, conforme a fórmula:

$N p=\frac{P m-P \operatorname{mín}}{P \operatorname{má} x-P \operatorname{mín}}$

Onde Np é o parâmetro normalizado; Pm o parâmetro medido da sub-bacia; Pmín o parâmetro mínimo medido entre as sub-bacias; e Pmáx o parâmetro máximo medido, gerando um valor entre 0 e 1.

Os parâmetros foram classificados conforme a Tabela 2. Para os parâmetros dos indicadores de Força Motriz e Pressão, quanto maior o índice obtido, maior sua capacidade de alteração do ambiente, ou seja, quanto mais próximo de 1 (Muito Alto). Já para os parâmetros dos indicadores Estado, Impacto e Resposta ocorre o inverso, quanto maior o índice obtido, melhor a condição e a capacidade de resposta aos impactos tem a bacia (Ótimo). As exceções são os parâmetros IDH-M, Vazão 
Média Outorgada para Captações Superficiais, Vazão Média Outorgada para Captações Subterrâneas e os de Incidência de Doenças de Veiculação Hídrica, que têm seus índices invertidos dentro dos seus respectivos indicadores, Pressão, Estado e Impacto, respectivamente. Para isso foi aplicada a seguinte fórmula:

$$
\operatorname{lin} v=1-I
$$

Onde linv é o índice invertido e I o índice calculado inicialmente.

Foram calculadas as médias dos parâmetros para cada sub-bacia, para os indicadores Força Motriz e Pressão integrados, e Estado, Impacto e Resposta também integrados, além da média para a BHRM (Tabela 3). Após, no programa QGIS 2.18.9, foram gerados o mapa síntese dos indicadores de Força Motriz e Pressão, o mapa síntese dos indicadores de Estado, Impacto e Resposta, e o mapa síntese da situação da BHRM.

Tabela 2 - Classificação dos índices da matriz FPEIR e da situação da BHRM

\begin{tabular}{cccccc}
\hline $\begin{array}{c}\text { Parâmetros de Força } \\
\begin{array}{c}\text { Motriz, Pressão e } \\
\text { Impacto }\end{array}\end{array}$ & Índice & $\begin{array}{c}\text { Parâmetros de } \\
\text { Estado e } \\
\text { Resposta }\end{array}$ & Índice & $\begin{array}{c}\text { Síntese da } \\
\text { situação da } \\
\text { BHRM }\end{array}$ & Índice \\
\hline Muito baixo & 0 a 0,20 & Ótimo & 0,80 a 1,00 & Ótima & 0,80 a 1,00 \\
Baixo & 0,20 a 0,40 & Bom & 0,60 a 0,80 & Boa & 0,60 a 0,80 \\
Médio & 0,40 a 0,60 & Regular & 0,40 a 0,60 & Regular & 0,40 a 0,60 \\
Alto & 0,60 a 0,80 & Ruim & 0,20 a 0,40 & Ruim & 0,20 a 0,40 \\
Muito alto & 0,80 a 1,00 & Péssimo & 0 a 0,20 & Péssima & 0 a 0,20 \\
\hline
\end{tabular}

Fonte: elaborado pelos autores

Os dados disponíveis apenas para municípios foram adaptados para que se obtivesse informações aproximadas agregadas por bacia hidrográfica. Para os dados de população, a população urbana foi considerada circunscrita à área urbana, conforme o mapeamento de uso e cobertura, e a população rural no restante do território municipal. A partir disso, considerou-se a população de um município que está contida em determinada bacia, proporcional à área do município dentro da bacia.

Dados de abastecimento de água, rede e tratamento de esgoto, geração e coleta de resíduos sólidos e incidência de doenças de veiculação hídrica foram agregados por bacia proporcionalmente à população. Os dados de estabelecimentos econômicos foram distribuídos proporcionalmente às áreas dos município dentro das bacias.

Já os dados disponíveis por bacia hidrográfica foram mantidos, mesmo com algumas diferenças na delimitação das áreas de contribuição em relação às da ANA, devido às metodologias de mapeamento diferentes. 


\section{RESULTADOS E DISCUSSÃO}

Com os índices gerados a partir dos parâmetros levantados, foi construída a matriz FPEIR (Tabela 3) e produzidos três mapas, um com a síntese dos indicadores de Força Motriz e Pressão (Mapa 4), que apresenta a influência das atividades antrópicas sobre a bacia; outro mapa sintetizando os indicadores Estado, Impacto e Resposta, apresentando a vulnerabilidade da bacia (Mapa 5); e o mapa de síntese dos cinco indicadores, mostrando a situação geral da BHRM (Mapa 6). A matriz e os mapas foram classificados segundo a Tabela 2. A seguir, desenvolveu-se a análise das relações entre os indicadores da matriz FPEIR e o mapeamento dos mesmos.

Tabela 3 - Matriz FPEIR

\begin{tabular}{|c|c|c|c|c|c|c|c|c|c|c|}
\hline Indicador / Parâmetro & BHRM & BHRM-1 & BHRM-2 & BHRM-3 & BHRM-4 & BHRM-5 & BHRM-6 & BHRM-7 & BHRM-8 & BHRM-9 \\
\hline $\begin{array}{l}\text { Taxa geométrica de } \\
\text { crescimento anual }\end{array}$ & 0,59 & 1,00 & 0,81 & 0,39 & 0,84 & 0,00 & 0,83 & 0,70 & 0,25 & 0,54 \\
\hline Densidade demográfica & 0,26 & 0,40 & 0,08 & 0,72 & 0,00 & 1,00 & 0,01 & 0,05 & 0,02 & $\overline{0,}$ \\
\hline Taxa de urbanização & 0,27 & 1,00 & 0,63 & 0,19 & 0,29 & - & 0,07 & 0,24 & - & - \\
\hline Área urbana & 0,30 & 0,86 & 0,52 & 1,00 & 0,09 & - & 0,04 & 0,22 & - & - \\
\hline $\begin{array}{l}\text { Estabelecimentos } \\
\text { agropecuários }\end{array}$ & 0,41 & 0,04 & 1,00 & 0,00 & 0,89 & 0,01 & 0,89 & 0,44 & 0,04 & 0,37 \\
\hline Pecuária & 0,35 & 0,08 & 1,00 & 0,00 & 0,55 & 0,00 & 0,74 & 0,32 & 0,12 & 0,35 \\
\hline E Suinocultura & 0,31 & 0,23 & 0,32 & 0,03 & 1,00 & 0,00 & 0,34 & 0,51 & 0,01 & 0,30 \\
\hline 은 Avicultura & 0,14 & 0,03 & 1,00 & 0,00 & 0,01 & 0,00 & 0,17 & 0,03 & 0,01 & 0,02 \\
\hline 후 Área de agricultura & 0,38 & 0,28 & 0,34 & 0,68 & 0,22 & 1,00 & 0,44 & 0,45 & 0,00 & 0,0 \\
\hline Área de silvicultura & 0,28 & 1,00 & 0,41 & 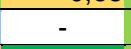 & 0,33 & - & 0,71 & 0,08 & & -1 \\
\hline $\begin{array}{l}\text { Estabelecimentos } \\
\text { industriais }\end{array}$ & 0,27 & 0,09 & 1,00 & 0,00 & 0,29 & 0,01 & 0,69 & 0,28 & 0,01 & 0,05 \\
\hline $\begin{array}{l}\text { Estabelecimentos de } \\
\text { comércio }\end{array}$ & 0,26 & 0,03 & 1,00 & 0,00 & 0,22 & 0,00 & 0,25 & 0,35 & 0,01 & 0,47 \\
\hline $\begin{array}{l}\text { Estabelecimentos de } \\
\text { serviço }\end{array}$ & 0,37 & 0,20 & 0,90 & 0,02 & 0,65 & 0,02 & 1,00 & 0,44 & 0,00 & 0,12 \\
\hline Demanda por animais & 0,29 & 0,20 & 0,77 & 0,00 & 1,00 & 0,49 & 0,02 & 0,04 & 0,05 & 0,02 \\
\hline Demanda para irrigação & 0,20 & 0,04 & 1,00 & 0,03 & 0,23 & 0,37 & 0,12 & 0,06 & 0,00 & 0,00 \\
\hline Demanda urbana & 0,24 & 1,00 & 0,85 & 0,09 & 0,07 & 0,06 & 0,00 & 0,09 & - & - \\
\hline Demanda total & 0,36 & 0,25 & 0,93 & 0,08 & 0,62 & 1,00 & 0,31 & 0,17 & - & 0,00 \\
\hline $\begin{array}{l}\text { Outorgas superficiais } \\
\text { em relação à área }\end{array}$ & 0,16 & 0,37 & - & - & 1,00 & - & - & 0,00 & 0,00 & 0,10 \\
\hline $\begin{array}{l}\text { Outorgas subterrâneas } \\
\text { em relação à área }\end{array}$ & 0,11 & - & - & - & 1,00 & - & - & 0,00 & - & - \\
\hline $\begin{array}{l}\text { Wू Proporção de outorgas } \\
\varrho \\
\stackrel{2}{2} \text { superficiais em relação } \\
\text { ao total }\end{array}$ & 0,16 & 0,09 & - & - & 1,00 & - & - & 0,22 & 0,04 & 0,09 \\
\hline $\begin{array}{l}\text { Proporção de outorgas } \\
\text { subterrâneas em } \\
\text { relação ao total }\end{array}$ & 0,22 & - & - & - & 1,00 & - & - & 1,00 & - & - \\
\hline Resíduo sólido urbano & 0,29 & 1,00 & 0,81 & 0,05 & 0,22 & 0,00 & 0,15 & 0,01 & 0,04 & 0,32 \\
\hline $\begin{array}{l}\text { Área de solo exposto } \\
\text { em relação à área total }\end{array}$ & 0,20 & 1,00 & 0,39 & 0,07 & 0,08 & 0,03 & 0,19 & 0,00 & - & - \\
\hline$\overline{\mathrm{IDH}-\mathrm{M}}$ & 0,51 & 0,00 & 0,39 & 0,08 & 0,67 & 0,08 & 0,64 & 0,77 & 0,98 & 1,00 \\
\hline $\begin{array}{l}\text { Síntese dos indicadores de } \\
\text { FM e P }\end{array}$ & 0,29 & 0,42 & 0,71 & 0,18 & 0,51 & 0,24 & 0,38 & 0,27 & 0,10 & 0,22 \\
\hline $\begin{array}{l}\text { Proporção de } \\
\text { parâmetros nos padrões }\end{array}$ & 0,33 & 0,00 & 0,00 & 0,00 & 0,00 & 0,00 & 0,00 & 1,00 & 1,00 & 1,00 \\
\hline $\begin{array}{l}\text { Proporção de amostras } \\
\text { com balneabilidade } \\
\text { o própria }\end{array}$ & 1,00 & 1,00 & - & - & - & - & - & - & - & - \\
\hline $\begin{array}{l}\frac{\pi}{\omega} \text { Vazão média outorgada } \\
w \text { para captações } \\
\text { superficiais }\end{array}$ & 0,64 & - & - & - & 0,00 & - & - & 0,93 & - & 1,0 \\
\hline $\begin{array}{l}\text { Vazão média outorgada } \\
\text { para captações } \\
\text { subterrâneas }\end{array}$ & 0,50 & - & - & - & 0,00 & - & - & 1,00 & - & - \\
\hline ֻ In Incidência de dengue & 0,86 & 0,98 & 0,94 & 1,00 & 0,00 & 1,00 & 1,00 & 0,87 & 1,00 & $\overline{0,98}$ \\
\hline É Incidência de hepatite A & 0,73 & 0,69 & 0,29 & 0,95 & 0,00 & 0,99 & 0,80 & 0,85 & 1,00 & $0, c$ \\
\hline
\end{tabular}




\begin{tabular}{|c|c|c|c|c|c|c|c|c|c|c|}
\hline \multirow{2}{*}{$\begin{array}{l}\text { Incidência de } \\
\text { leptospirose }\end{array}$} & \\
\hline & 0,30 & 0,80 & 0,45 & 0,03 & 1,00 & 0,01 & 0,30 & 0,10 & 0,00 & 0,00 \\
\hline Incidência de malária & 0,75 & 0,00 & 0,27 & 0,83 & 0,83 & 1,00 & 0,87 & 0,93 & 1,00 & 1,00 \\
\hline $\begin{array}{l}\text { Incidência de doenças } \\
\text { de veiculação hídrica }\end{array}$ & 0,75 & 0,72 & 0,43 & 0,96 & 0,00 & 0,99 & 0,81 & 0,86 & 1,00 & 0,99 \\
\hline $\begin{array}{l}\text { Índice de atendimento } \\
\text { de água }\end{array}$ & 0,41 & 0,03 & 1,00 & 0,00 & 0,00 & 0,00 & 0,69 & 0,28 & 0,67 & 0,99 \\
\hline $\begin{array}{l}\text { Indice de atendimento } \\
\text { com rede de esgoto }\end{array}$ & 0,32 & 0,04 & 1,00 & 0,00 & 0,00 & 0,00 & 0,45 & 0,20 & 0,44 & 0,76 \\
\hline $\begin{array}{l}\text { Indice de tratamento de } \\
\text { esgoto }\end{array}$ & 0,25 & 0,00 & 1,00 & 0,00 & 0,00 & 0,00 & 0,00 & 0,25 & 0,00 & 0,96 \\
\hline $\begin{array}{l}\text { Taxa de cobertura da } \\
\text { coleta de resíduos }\end{array}$ & 0,50 & 0,04 & 0,59 & 0,00 & 0,69 & 1,00 & 0,27 & 0,96 & 0,22 & 0,76 \\
\hline $\begin{array}{l}\text { Densidade da rede de } \\
\text { monitoramento da água } \\
\text { ๘ superficial }\end{array}$ & 0,13 & 0,15 & 0,00 & 1,00 & 0,00 & 0,00 & 0,00 & 0,05 & 0,00 & 0,00 \\
\hline $\begin{array}{l}\text { Amostras para } \\
\text { क balneabilidade das } \\
\simeq \text { praias }\end{array}$ & 1,00 & 1,00 & - & - & - & - & - & - & - & - \\
\hline $\begin{array}{l}\text { Área de mata em } \\
\text { relação à área total }\end{array}$ & 0,30 & 0,09 & 0,16 & 0,01 & 0,22 & 0,00 & 0,16 & 0,21 & 0,87 & 1,00 \\
\hline UC & 0,21 & 0,08 & 0,00 & 0,00 & 0,00 & 0,00 & 0,11 & 0,18 & 1,00 & 0,47 \\
\hline UC de proteção integral & 0,19 & 0,08 & 0,00 & 0,00 & 0,00 & 0,00 & 0,11 & 0,18 & 1,00 & 0,32 \\
\hline UC de uso sustentável & 0,11 & 0,00 & 0,00 & 0,00 & 0,03 & 0,00 & 0,00 & 0,00 & 0,00 & 1,00 \\
\hline Terras indígenas & 0,11 & 0,00 & 0,00 & 0,00 & 1,00 & 0,00 & 0,00 & 0,00 & 0,00 & 0,00 \\
\hline Quilombolas & 0,11 & 0,00 & 0,00 & 0,00 & 0,00 & 0,00 & 0,00 & 0,00 & 0,00 & 1,00 \\
\hline Área abrangida por PSB & 0,64 & 1,00 & 0,90 & 0,66 & 0,66 & 0,50 & 0,66 & 0,66 & 0,00 & 0,66 \\
\hline $\begin{array}{l}\text { Área abrangida por } \\
\text { PGRS }\end{array}$ & 0,58 & 0,67 & 0,70 & 1,00 & 0,16 & 1,00 & 0,83 & 0,50 & 0,00 & 0,33 \\
\hline $\begin{array}{l}\text { Síntese dos indicadores de } \\
\text { E, I e R }\end{array}$ & 0,47 & 0,35 & 0,41 & 0,34 & 0,22 & 0,34 & 0,37 & 0,48 & 0,48 & 0,71 \\
\hline $\begin{array}{l}\text { Síntese da situação da } \\
\text { BHRM }\end{array}$ & 0,59 & 0,47 & 0,35 & 0,58 & 0,35 & 0,55 & 0,50 & 0,60 & 0,69 & 0,74 \\
\hline
\end{tabular}

Fonte: elaborado pelos autores

\section{Análise dos indicadores}

No indicador de Força Motriz, destaca-se a Taxa Geométrica de Crescimento Anual (TGCA) pela acentuada diminuição da população em todas as sub-bacias, exceto pela BHRM-1, no período 2000/2010. Dessas, a BHRM-5, com $-32,3 \%$, BHRM-8, com -24,3\% e BHRM-3, com -19,8\%, são as mais expressivas. Apesar disso, a BHRM-5 possui a maior densidade demográfica das nove sub-bacias, com $1.133,1 \mathrm{hab} / \mathrm{km}^{2}$, seguida da BHRM-3, com $828 \mathrm{hab} / \mathrm{km}^{2}$. No entanto, a capacidade de alteração da taxa é Muito Alta e Alta em quatro sub-bacias, contribuindo para o índice Médio da BHRM. Já a densidade demográfica é Muito Alta apenas na BHRM5 .

As taxas de urbanização são baixas, sendo nulas nas BHRM-5, BHRM-8 e BHRM-9. A maioria das sub-bacias tem índice entre Baixo e Muito Baixo, tendo a BHRM-1 índice Muito Alto. Quanto à área urbana, as sub-bacias próximas à foz do rio Mampituba têm índices Muito Alto e Média, com a BHRM-5, BHRM-8 e BHRM-9 não contendo uso urbano.

Quanto aos estabelecimentos agropecuários, dos 6.484 existentes na BHRM, a BHRM-2, BHRM-4 e BHRM-6 concentram 26,6\%, 23,8\% e $23,6 \%$, 
respectivamente, tendo índice Muito Alto de comprometimento, contribuindo para que a totalidade da BHRM tenha índice Médio. Já para o efetivo de rebanhos, a BHRM-2 e BHRM-6 concentram as maiores quantidades de gado. A BHRM-4 tem o maior rebanho de suínos e a BHRM-2 o maior número de aves. No geral, a BHRM tem índice Baixo quanto à pecuária e suinocultura, e Muito Baixo quanto à avicultura. Entretanto, BHRM-2, BHRM-4 e BHRM-6 contribuem com índices Muito Alto e Alto.

Quanto às áreas cultivadas, a BHRM tem 22,4\% de sua área usada para agricultura e 3,3\% para silvicultura. A BHRM-1 se destaca com a maior área de cultivo, com 0,2\% para silvicultura. Quanto a essa última categoria de uso, as bacias apresentam índices variados, com BHRM-1, BHRM-2 e BHRM-6, indo de Médio à Muito Alto. Já quanto ao uso agrícola, BHRM-3, BHRM-5, BHRM-6 e BHRM-7 é que variam de Médio a Muito Alto.

A BHRM-2 e a BHRM-6, concentram a maior parte dos estabelecimentos industriais e de serviços da BHRM. Já o comércio é concentrado na BHRM-2, com 42,2\%. A maioria das sub-bacias tem índice Muito Baixo de alteração, tendo a BHRM índices Muito Baixo em relação à quantidade de estabelecimentos.

No indicador Pressão, estão disponíveis dados dos parâmetros de demanda por animais, irrigação, urbana e demanda total. Dessas, a maior demanda é para irrigação, seguida do uso urbano. Sendo a BHRM-1 a com maior demanda com índices de comprometimento Muito Alto. BHRM-4 e BHRM-5 destacam-se pelo comprometimento Alto e Muito Alto da demanda total. Entretanto, a respeito da quantidade e proporção de captações, a BHRM-4 distingue-se com grau Muito Alto em relação às outorgas, tanto superficiais quanto subterrâneas. A BHRM-7 também apresenta grau Muito Alto em relação à Proporção de Outorgas Subterrâneas. No geral, A BHRM tem índices entre Baixo e Muito Baixo.

Quanto aos resíduos sólidos urbanos gerados, a BHRM apresenta 70,1 t/dia, sendo a BHRM-1 e a BHRM-2 as sub-bacias que mais contribuem, com 29,9 t/dia e 24,8 t/dia, respectivamente, com grau Muito Alto. As demais sub-bacias apresentam grau Muito Baixo e Baixo, e a BHRM, Baixo de comprometimento.

A área de solo exposto na BHRM compreende 1,2\% da área, tendo maior contribuição da BHRM-1, com $13,2 \%$ da área e nível Muito Alto de comprometimento. Todas as demais bacias apresentam grau Muito Baixo e Baixo. A maior parte das áreas de solo exposto compreende dunas, entorno de áreas urbanas e áreas provavelmente agrícolas de culturas temporárias. 
Para o IDH-M, a BHRM apresenta grau Médio, com valor de 0,619. As subbacias do Baixo Mampituba contribuem com índices Muito Baixo e Baixo. Entretanto, a BHRM-4 e as bacias do Alto Mampituba ostentam grau Alto e Muito Alto, com IDHM abaixo de 0,600.

Para os quatro parâmetros do indicador Estado, a maioria das sub-bacias não possui dados disponíveis, já que existem apenas dois pontos de monitoramento da qualidade da água, um na BHRM-1 e outro na BHRM-7. Além disso, apenas alguns parâmetros de qualidade são verificados nesses pontos, impossibilitando o cálculo do Índice de Qualidade da Água (IQA) e, dessa maneira, prejudicando um diagnóstico geral da BHRM. Foi estabelecida a proporção de parâmetros que estão dentro dos padrões de qualidade oficial (CONAMA, 2005), preferencialmente a Classe 2. Também se considerou que cada ponto de monitoramento relaciona-se às bacias situadas a montante do ponto de monitoramento. Sendo assim, as sub-bacias BHRM-1 até BHRM-6, referentes ao ponto MPT-001, possuem proporcionalmente 66,7\% dos parâmetros em conformidade à Resolução CONAMA 357/2005, apresentando estado relativo Péssimo. Ao mesmo tempo que as sub-bacias BHRM7 até BHRM-9, referentes ao ponto MPT-025, tem 83,3\% dos parâmetros dentro do padrão, apresentando estado Ótimo. A BHRM apresenta 75\% dos parâmetros com estado Ruim, conforme estabelece a legislação do CONAMA (2005).

Com os elementos disponíveis, a qualidade das águas das sub-bacias do baixo e médio Mampituba apresenta condição Péssima, enquanto que a montante a qualidade é Ótima, tendo a BHRM, no geral, uma classificação Ruim. A balneabilidade das praias também foi uma das variáveis consideradas para compor a matriz FPEIR. Foram quatro pontos de coleta de amostras, todos localizados no município de Torres, na BHRM-1. Os resultados de todas as amostras coletadas corroboram no entendimento de que as praias são próprias para banho. Assim, a BHRM-1, única com pontos de coleta, tem índice Ótimo.

Quanto às vazões médias outorgadas para captações superficiais e subterrâneas, nem todas as sub-bacias possuem outorgas, sendo três para captações superficiais e duas para subterrâneas. As captações superficiais apresentam as maiores vazões. As sub-bacias do Alto Mampituba apresentam estado Ótimo, entretanto a BHRM-4 tem grau Péssimo, contribuindo para os estados Bom e Regular da bacia em relação às captações superficiais e subterrâneas, respectivamente. 
As doenças de veiculação hídrica são o parâmetro encontrado para o indicador Impacto, considerando as quatro doenças em que existem dados sistematizados: dengue, hepatite $A$, leptospirose e malária. A BHRM apresenta estado Bom, com 36,8 casos a cada 10.000 habitantes. Hepatite A é a doença com maior ocorrência, 25 casos. A maioria das sub-bacias apresenta estado Ótimo. A maior quantidade de incidências ocorre no Baixo Mampituba, sendo a BHRM-2 e a BHRM-4 as mais críticas. Destaca-se também a ocorrência considerável de leptospirose, contribuindo para o estado Ruim da BHRM neste parâmetro. Cabe ressaltar que os números de ocorrências de doenças de veiculação hídrica na BHRM, em termos absolutos, são baixos. Os índices desfavoráveis na matriz são relativos à amplitude das ocorrências registradas.

São 14 os parâmetros do indicador Resposta considerados. No parâmetro Abastecimento de Água, a BHRM apresenta um índice de atendimento considerado Regular. Quatro sub-bacias apresentam estado Péssimo, enquanto apenas duas têm um estado Ótimo. Na BHRM, apenas 41,5\% da população é atendida com abastecimento de água, sendo que na BHRM-3 e BHRM-5, o atendimento é zero. A BHRM-2 e BHRM-9 apresentam mais de $60 \%$ da população atendida.

O índice de atendimento com rede de esgoto alcança 51,3\% na BHRM, resultando em um nível Ruim. Apesar da BHRM-2 apresentar 89,9\% de atendimento em rede de esgoto, a BHRM-3, BHRM-4, BHRM-5 e BHRM-7 têm índice zero e estado Péssimo, juntamente com a BHRM-1. O índice de tratamento de esgoto é péssimo em seis sub-bacias, e ruim em uma. Na totalidade, a BHRM apresenta índice Ruim do serviço de tratamento, com apenas $23,6 \%$ da população atendida.

A taxa de cobertura da coleta de resíduos é de $82,1 \%$ na BHRM, ultrapassando 95\% na BHRM-5 e BHRM-7. Entretanto, cinco das demais subbacias, sendo três no Baixo Mampituba, contribuem para que o serviço tenha grau Regular na BHRM.

Considerando os dois pontos de monitoramento da qualidade da água mantidos pelo órgão de controle ambiental gaúcho, a FEPAM, a densidade da rede de monitoramento é Péssima, exceto a BHRM-3, com apenas duas sub-bacias sendo atendidas, e mesmo assim com número de pontos insuficientes. A BHRM apresenta densidade de 1,7 ponto a cada $1.000 \mathrm{~km}^{2}$.

A cobertura de mata na BHRM ocupa $24,1 \%$ da sua área, sendo que na BHRM-9 a mata ocupa quase $9 \%$. Na maioria das sub-bacias, a cobertura de mata é baixa, apresentando estado Péssimo. Já em relação às áreas protegidas, as 
unidades de conservação ocupam 15,1\% da BHRM, abrangendo 85,3\% da BHRM-8. As unidades de proteção integral predominam com 13,3\% da área da BHRM. A BHRM e as sub-bacias do Baixo e Médio Mampituba apresentam grau Péssimo em relação aos parâmetros de unidades de conservação.

As terras indígenas ocupam apenas $0,2 \%$ da área da BHRM-4 com 0 assentamento Campo Bonito. A comunidade quilombola São Roque ocupa 27,9\% da BHRM-9, sendo 4,2\% da BHRM. Todas as sub-bacias onde não há terras indígenas e quilombos têm grau Péssimo.

Em relação aos instrumentos de gestão, foram consideradas as áreas da BHRM e sub-bacias abrangidas por Planos Municipais de Saneamento Básico (PMSB) e Planos de Gerenciamento de Resíduos Sólidos (PMGRS). Quanto ao primeiro, a BHRM-8 tem menos de $1 \%$ de sua área abrangida, a maioria das subbacias tem estado Bom e Ótimo, apenas a BHRM-5 apresenta estado Regular. Quanto ao segundo instrumento de gestão, as sub-bacias do Alto Mampituba são problemáticas, com estado de Regular à Péssimo, além da BHRM-4. A BHRM apresenta índice Bom quanto à sua área abrangida por PMSB, e Regular quanto à PMGRS.

\section{Síntese da situação dos recursos hídricos da BHRM}

Quanto à influência dos indicadores Força Motriz e Pressão, ou seja, a capacidade dos primeiros gerarem os segundos, Estado, Impacto e Resposta, e a intensidade desses últimos, a BHRM-2 é a com maior influência, classificada como Alta, seguida da BHRM-4 e BHRM-1, classificadas como Média (Mapa 4).

A BHRM-2 tem maior quantidade de parâmetros classificados como Muito Alto (Tabela 3). A urbanização aliada às atividades industriais e comerciais, notadamente na região dos municípios de Araranguá e Sombrio exerce influência Muito Alta sobre o ambiente da bacia, gerando pressão por demanda urbana de água e elevando a produção de resíduos sólidos. A atividade agrícola também é Muito Alta, intensificando a pressão por demanda de água para irrigação e dessedentação de animais e, juntamente com a demanda urbana, incrementando a demanda total.

As sub-bacias BHRM-4 e BHRM-1 apresentam influência Média. Na primeira, além da urbanização, a atividade agrícola demanda de água para animais e captações de água superficiais e subterrâneas. É a bacia com maior número de outorgas. Já na segunda, principalmente a urbanização intensa na foz do rio 
Mampituba, gera pressão por demanda de água e aumenta a produção de resíduos sólidos, além da área usada para silvicultura ser proporcionalmente grande na bacia. A área de solo exposto também é considerável, mas boa parte está associada às faixas de dunas.

As demais sub-bacias têm influência Baixa e Muito Baixa (Mapa 4). Entretanto, cabe destacar a urbanização e as atividades agrícolas, industriais e de serviços, juntamente com o IDH-M na BHRM-6, fazendo com que esteja no limite de Baixo para Média. A BHRM-7 também chama atenção, mas está menos comprometida. Já as BHRM-8 e BHRM-9 têm influência Muito Baixa, porém seus IDH-M geram uma pressão importante.

Os estabelecimentos agropecuários são bastante numerosos na BHRM-2, BHRM-4 e BHRM-6. Apesar das áreas urbanas não serem grandes em extensão, a urbanização tem forte influência no Baixo e Médio Mampituba. Portanto, áreas e estabelecimentos agrícolas, que têm potencial de gerar poluição difusa, e a industrialização, aliados à urbanização na foz do Mampituba, são as principais forças que geram pressão, principalmente pela demanda de água e produção de resíduos sólidos. De modo geral, os indicadores têm influência Baixa sobre a BHRM.

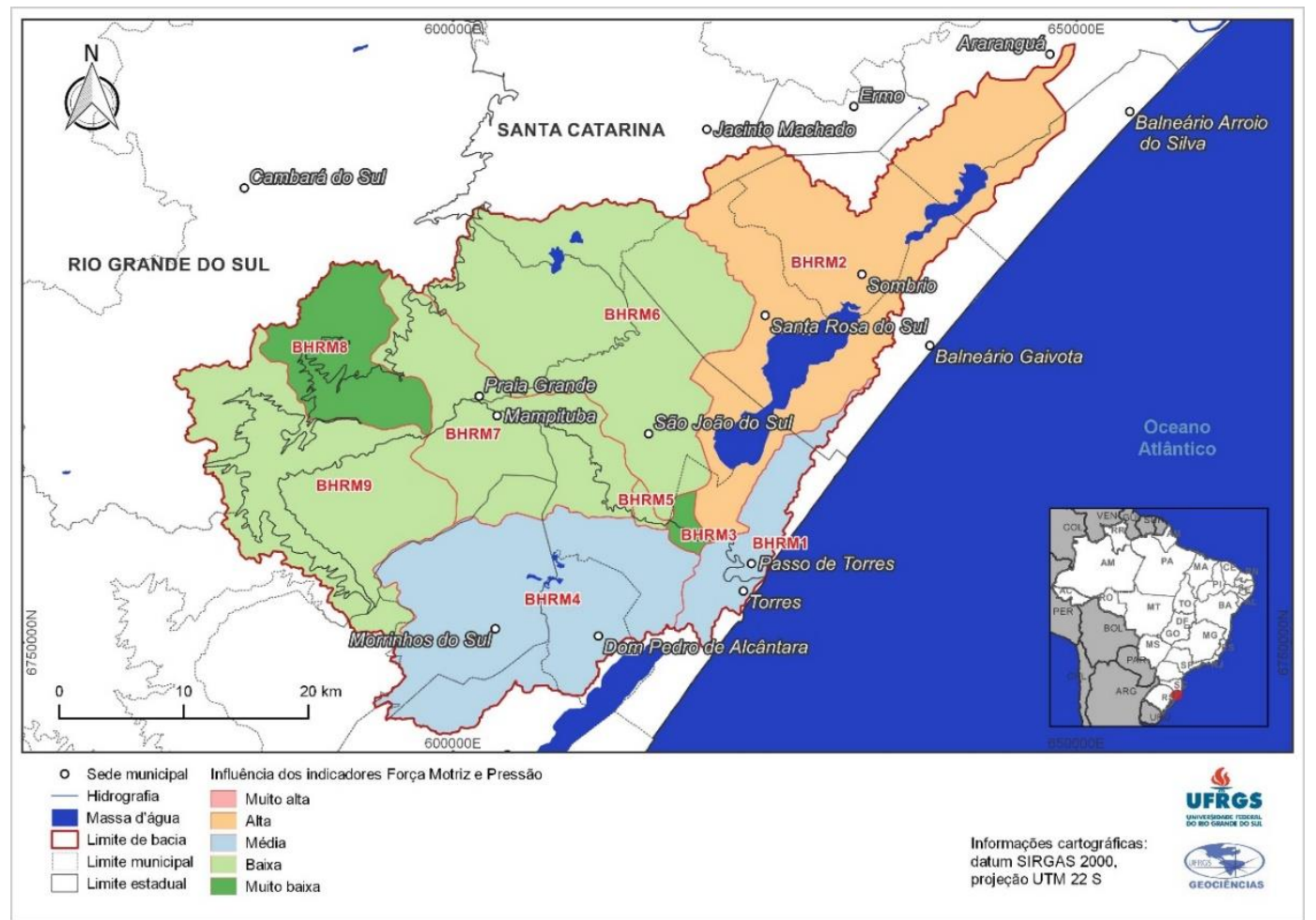

Mapa 4 - Síntese dos indicadores de Força Motriz e Pressão (Fonte: elaborado pelos autores)

Quanto à vulnerabilidade da BHRM, refletida pelos indicadores Estado, Impacto e Resposta, apenas a BHRM-9 apresenta condição Regular. Nas demais a condição é Regular ou Ruim (Mapa 5). O indicador Impacto, através dos parâmetros 
de incidência de doenças de veiculação hídrica, juntamente com os planos de saneamento básico e de resíduos sólidos, são os que mais colaboram para amenizar a vulnerabilidade da bacia. No entanto, a incidência de leptospirose, principalmente no Alto Mampituba, é elevada.

Todas as sub-bacias apresentam deficiências de infraestrutura de saneamento básico, como abastecimento de água, rede e tratamento de esgoto, com a maioria dos parâmetros em condição Péssima. Destacam-se as bacias BHRM-4, BHRM-5 e BHRM-6, onde não há esses serviços. A bacia, de modo geral, é muito vulnerável à poluição. Além disso, o monitoramento da qualidade da água é insuficiente, com apenas dois pontos em toda a BHRM (Mapa 5) e, mesmo assim, nem todos os parâmetros de qualidade são verificados.

A cobertura natural de mata e as áreas protegidas apresentam condição Péssima na maioria das sub-bacias. Exceção para a BHRM-8, que chega a ter $85 \%$ de sua área abrangida por unidades de conservação, e a BHRM-9. As terras indígenas e quilombos contribuem para reduzir a vulnerabilidade da BHRM-4 e da BHRM-9.

Os instrumentos de gestão, ou seja, planos de saneamento básico e de resíduos sólidos, contribuem bastante para diminuir a vulnerabilidade da BHRM. A BHRM-1, BHRM-3 e BHRM-5 estão com 100\% de suas áreas abrangidas por pelo menos um dos planos. A BHRM-4 e a BHRM-8 mostram as piores situações, com condição Péssima, com menos de $1 \%$ de área abrangida.

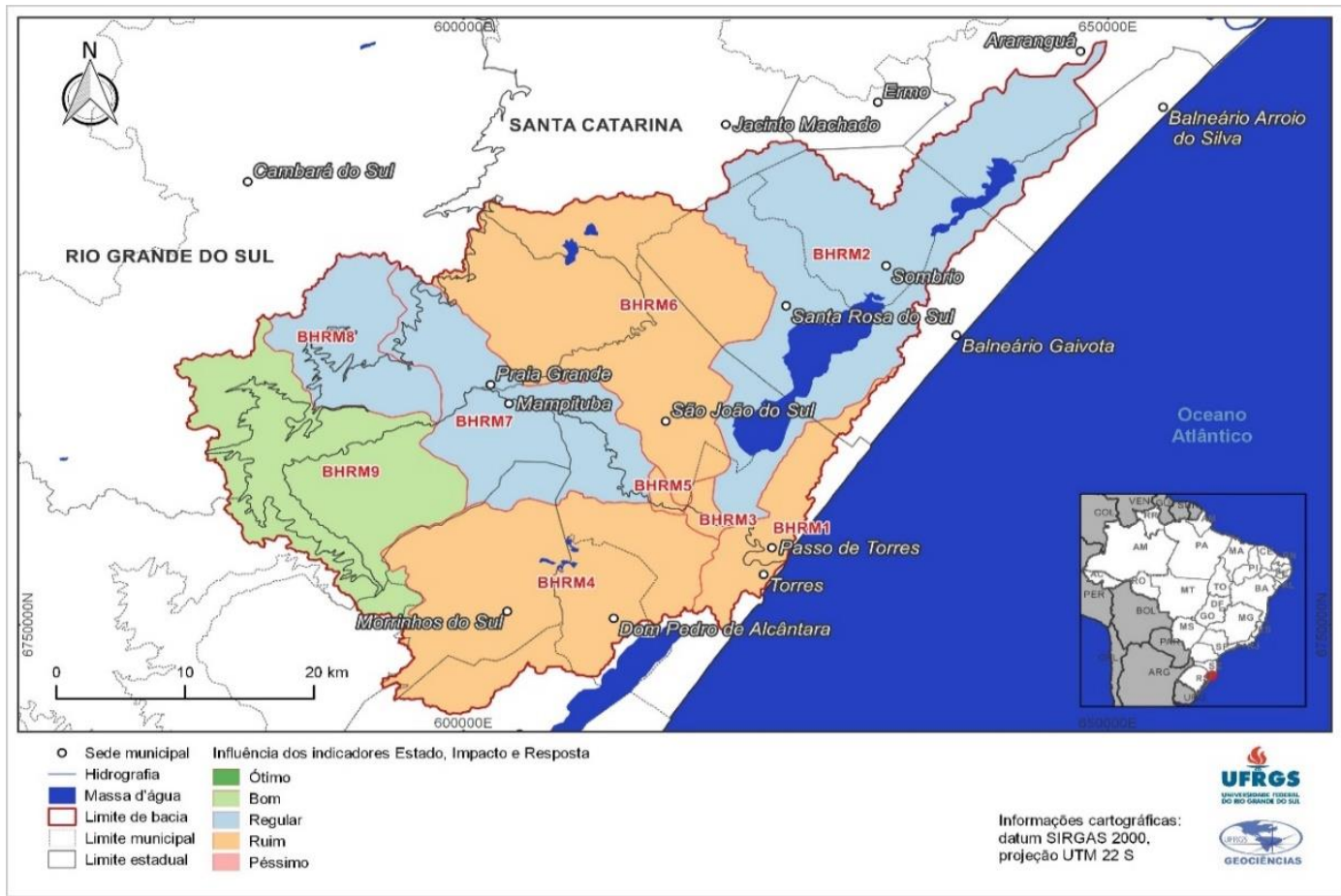

Mapa 5 - Síntese dos indicadores de Pressão, Impacto e Resposta (Fonte: elaborado pelos autores) 
Em síntese, verifica-se que a situação da BHRM é Regular. A principal atividade geradora de pressão sobre os recursos hídricos da BHRM é a agrícola, que aumenta a demanda e as captações de água, além de potencial geradora de poluição difusa no ambiente. As sub-bacias que acompanham o leito do rio Mampituba também estão na mesma condição Regular (Mapa 6) devido à urbanização na foz do rio Mampituba e a atividade agrícola no Médio Mampituba, à falta de infraestrutura de saneamento básico e de áreas de proteção ambiental.

As bacias BHRM-2 e BHRM-4 têm as piores condições, em situação Ruim (Mapa 6). A primeira devido às atividades agrícolas e industriais, juntamente com a urbanização, e a deficiência da infraestrutura de saneamento básico. A segunda devido às atividades agrícolas, principalmente arrozeira. A inexistência de áreas protegidas também colabora para a situação das duas sub-bacias.

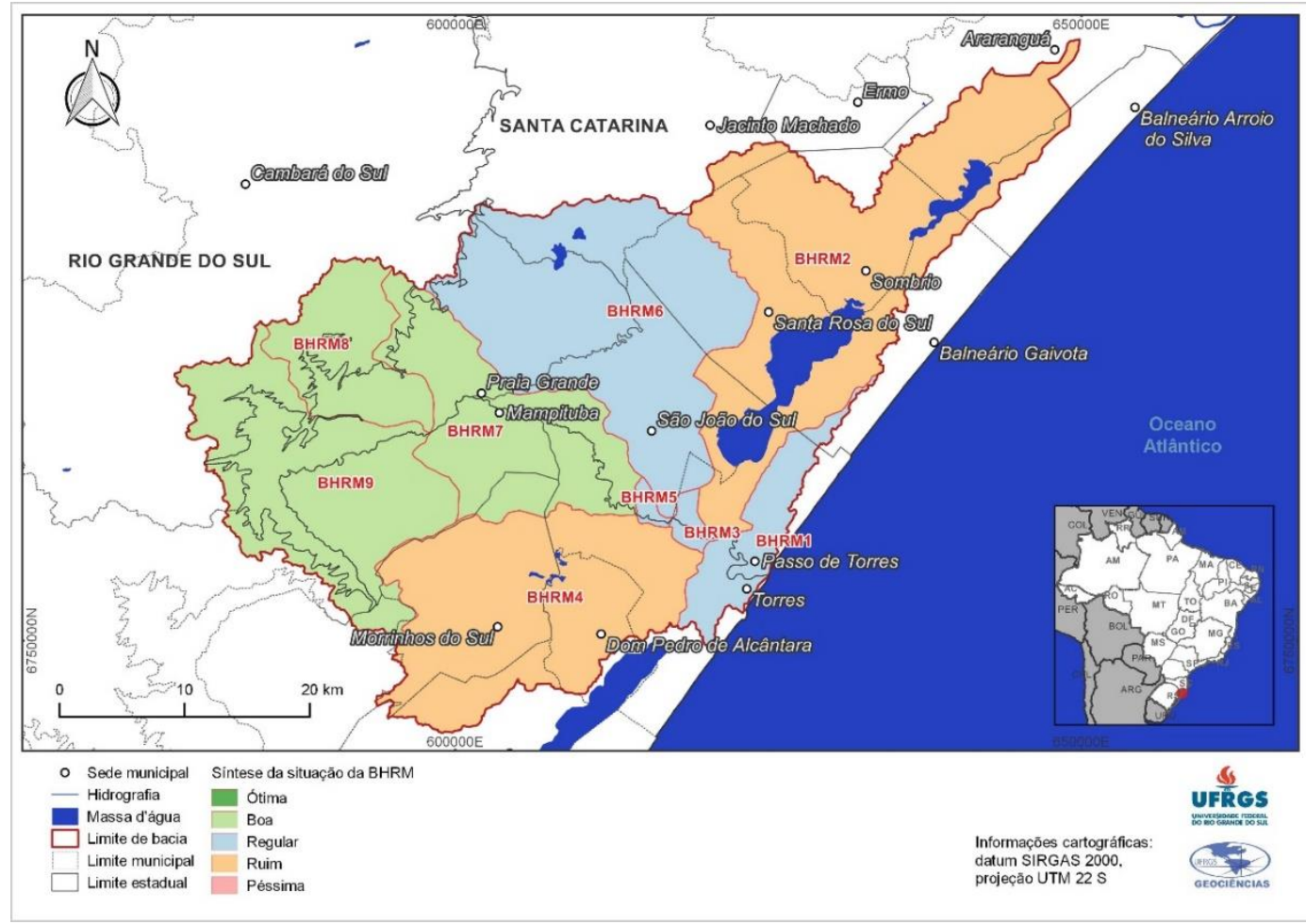

Mapa 6 - Síntese da situação dos recursos hídricos da BHRM (Fonte: elaborado pelos autores)

\section{CONSIDERAÇÕES FINAIS}

A BHRM compreende 18 municípios de dois estados brasileiros, Rio Grande do Sul e Santa Catarina, abrangendo quase 130 mil habitantes. Mesmo com a escassez de dados, a maior parte das informações utilizadas neste trabalho foi obtida em órgãos gaúchos e federais. De Santa Catarina há apenas dados municipais. A escassa informação sobre a bacia se reflete nas poucas ações de monitoramento, proteção e resposta às pressões antrópicas no ambiente, onde a 
atividade agrícola, em especial a atividade arrozeira e sua agroindústria, com grande potencial poluidor dos solos e dos recursos hídricos, juntamente com a industrialização e a urbanização, são os principais vetores. Frente a essas pressões, a bacia está vulnerável devido à deficiência da infraestrutura de saneamento, da insuficiência das ações de monitoramento e das áreas protegidas, configurando uma situação geral Regular em relação à sua sustentabilidade ambiental.

Diante dos aspectos observados, faz-se necessária a ampliação da rede de monitoramento da qualidade da água, das áreas protegidas e da melhoria da infraestrutura de saneamento. Também é necessária a criação de comitê que gerencie os dois lados da divisa estadual da bacia, que atualmente compreende apenas o lado do Rio Grande do Sul.

Para obter-se o diagnóstico da situação dos recursos hídricos da BHRM, o método da matriz FPEIR mostrou-se flexível para ser adaptado conforme os parâmetros e indicadores disponíveis. Além disso, ele abrange uma ampla gama de aspectos que influenciam na dinâmica socioambiental da bacia hidrográfica, e aliado ao SIG, permite apontar quais elementos estão prejudicando o ambiente e onde estão os principais problemas.

\section{AGRADECIMENTOS}

Aos professores Laurindo Antonio Guasselli e Ulisses Franz Bremer pelos valiosos apontamentos feitos neste estudo. À Universidade Federal do Rio Grande do Sul, através do Departamento de Geografia e do Instituto de Geociências, por proporcionar a realização deste trabalho.

\section{REFERÊNCIAS}

ALVARES, C. A. et al. Köppen's climate classification map for Brazil. Meteorologische Zeitschrift, Stuttgart, v. 22, n. 6, jan. 2014. p. 711-728.

ANA. Conjuntura dos recursos hídricos no Brasil 2013. Brasília: ANA, 2013. 432 p.

BASSO, L. A. A crise dos recursos hídricos. Boletim Gaúcho de Geografia, Porto Alegre, jun. 1999. p. 141-153.

BRASIL. Lei no 6.938, de 31 de agosto de 1981. Dispõe sobre a Política Nacional do Meio Ambiente, seus fins e mecanismos de formulação e aplicação, e dá outras providências, Brasília, 1981.

BRASIL. Lei no 7.661, de 8 de janeiro de 1997. Institui a Política Nacional de Recursos Hídricos, cria o Sistema Nacional de Gerenciamento de Recursos Hídricos, regulamenta 0 inciso XIX do art. 21 da CF, e altera 0 art. 1 da Lei no 8.001 , de 13 de 
março de 1990, que modificou a Lei no 7.990, de 28 de dezembro de 1989, Brasília, 1997.

COBRAPE. Plano das bacias hidrográficas dos rios Piracicaba, Capivari e Jundiaí 2010-2020. São Paulo. 2010. 815 p.

CONAMA. Resolução no 357, de 17 de março de 2005. Dispõe sobre a classificação dos corpos de água e diretrizes ambientais para o seu enquadramento, bem como estabelece as condições e padrões de lançamento de efluentes, e dá outras providências, Brasília, 2005.

EEA. Environmental indicators: typology and overview. EEA. Copenhague. 1999. 18 p.

HINATA, S. D. S.; BASSO, L. A. Qualidade da água associada ao cultivo de banana na subbacia hidrográfica do Rio das Pacas - RS. In: BASSO, L. A.; MOURA, N. S. V.;

STROHAECKER, T. M. Geografia: dinâmica, conflitos e proposições. Porto Alegre: wwlivros, 2017. 274 p.

IBGE. Mapa geológico. Folha Gravataí SH.22-X-C. 250.000. IBGE. Rio de Janeiro. 2003a. IBGE. Mapa geomorfológico. Folha Gravataí SH.22-X-C. 250.000. IBGE. Rio de Janeiro. 2003b.

IPT. Diagnóstico da situação dos recursos hídricos na Bacia Hidrográfica do Rio Grande (BHRG) - SP/MG (Relatório síntese - R3). IPT. São Paulo. 2008. 51 p.

IPT; PREFEITURA DE ITANHAÉM. Atlas ambiental do município de Itanhaém - 2012. São Paulo: Imprensa Oficial, 2012. 92 p.

IRRIGART. Relatório de situação dos recursos hídricos das bacias Piracicaba, Capivari e Jundiaí / Modelo CRHi - 2009. Piracicaba, p. 31. 2009.

KUNST, A. V.; MOURA, N. S. V. Impactos ambientais urbanos: o caso do setor norte do litoral gaúcho. In: BASSO, L. A.; MOURA, N. S. V.; STROHAECKER, T. M. Geografia: dinâmica, conflitos e proposições. Porto Alegre: wwlivros, 2017. 274 p.

MEDEIROS, A. V. D. Diagnóstico da situação hídrica da bacia Piancó-Piranhas-Açu no núcleo de desertificação do Seridó Potiguar. Natal: [s.n.], 2017. 84 p. Dissertação (Mestrado Profissional) - Programa de Pós-Graduação em Uso Sustentável dos Recursos Naturais, Instituto Federal de Educação, Ciência e Tecnologia do Rio Grande do Norte.

PERES, R. B.; SILVA, R. S. D. Interfaces da gestão ambiental urbana e gestão regional: análise da relação entre Planos Diretores Municipais e Planos de bacia Hidrográfica. urbe Revista Brasileira de Gestão Urbana, Curitiba, v. 5, n. 2, jul./dez. 2013. p. 13-25.

ROSSATO, M. S. Os climas do Rio Grande do Sul: variabilidade, tendências e tipologia. Porto Alegre: [s.n.], 2011. 240 p. Tese (Doutorado) - Programa de Pós-Graduação em Geografia, Instituto de Geociências, Universidade Federal do Rio Grande do Sul.

SÁNCHEZ, L. E. Avaliação de impacto ambiental - Conceitos e métodos. 2. ed. São Paulo: Oficina de Textos, 2013. 584 p.

SANTOS, R. F. D. Planejamento ambiental: teoria e prática. São Paulo: Oficina de Textos, 2004. $184 \mathrm{p}$. 
SOARES, A. B. et al. Revisando a estruturação do modelo DPSIR como base para um sistema de apoio à decisão para a sustentabilidade de bacias hidrográficas. Revista em Agronegócios e Meio Ambiente, Maringá, v. 4, n. 3, set./dez. 2011. p. 521-545.

SPERLING, M. V. Introdução à qualidade das águas e ao tratamento de esgotos. Belo Horizonte: Editora da UFMG, v. 1, 1996.

TUCCI, C. E. M.; MENDES, C. A. Avaliação ambiental integrada de bacia hidrográfica. Brasília: Ministério do Meio Ambiente, 2006. 302 p.

VAZ, C. A. B.; SILVEIRA, G. L. D. O modelo PEIR e base SIG no diagnóstico da qualidade ambiental em sub-bacia hidrográfica urbana. RBRH - Revista Brasileira de Recursos Hídricos, Porto Alegre, v. 19, n. 2, abr./jun. 2014. p. 281-298.

\section{NOTAS DE AUTOR}

\section{CONTRIBUIÇÃO DE AUTORIA}

Daniel Trespach Porto - Concepção, coleta e análise de dados, validação, visualização, elaboração do manuscrito, revisão e aprovação da versão final do trabalho

Luís Alberto Basso - Concepção, participação ativa da discussão dos resultados, revisão e aprovação da versão final do trabalho.

Tânia Marques Strohaecker - Concepção, participação ativa da discussão dos resultados, revisão e aprovação da versão final do trabalho.

\section{FINANCIAMENTO}

Não se aplica.

\section{CONSENTIMENTO DE USO DE IMAGEM}

Não se aplica.

APROVAÇÃO DE COMITÊ DE ÉTICA EM PESQUISA

Não se aplica.

\section{CONFLITO DE INTERESSES}

Não se aplica.

\section{LICENÇA DE USO}

Este artigo está licenciado sob a Licença Creative Commons CC-BY. Com essa licença você pode compartilhar, adaptar, criar para qualquer fim, desde que atribua a autoria da obra.

\section{HISTÓRICO}

Recebido em: 10-05-2018

Aprovado em: 31-10-2018 